\title{
The New Integrated Nuclear Medicine and Radiology Residency Program in The Netherlands: Why Do Residents Choose to Subspecialize in Nuclear Medicine and Why Not?
}

\author{
Ton Velleman ${ }^{1}$, Walter Noordzij ${ }^{1}$, Rudi A.J.O. Dierckx ${ }^{1}$, Yfke Ongena ${ }^{2}$, and Thomas C. Kwee ${ }^{1}$ \\ ${ }^{I}$ Department of Radiology, Nuclear Medicine, and Molecular Imaging, Medical Imaging Center, University Medical Center Groningen, \\ University of Groningen, Groningen, The Netherlands; and ${ }^{2}$ Faculty of Arts, Communication, and Information Sciences, University of \\ Groningen, Groningen, The Netherlands
}

See an invited perspective on this article on page 903.

\begin{abstract}
Our purpose was to explore the reasons that a resident chooses to enter the nuclear medicine subspecialty in the integrated nuclear medicine and radiology residency program in The Netherlands. Methods: A web questionnaire was developed and distributed among residents in the Dutch integrated nuclear medicine and radiology training program. Results: In total, 114 residents were included. The survey results revealed 4 categories of incentives to choose the nuclear medicine subspecialty: the expertise of nuclear medicine physicians and their quality of supervision in the training hospital; opportunities to do scientific research during and after residency; the diversity of pathologic conditions, radiotracers, examinations, and therapies in the training hospital; and the expectation that the role of hybrid imaging will increase in the future. The results also revealed 4 groups of disincentives to choose the nuclear medicine subspecialty: lack of collaboration and integration between nuclear medicine and radiology in some training hospitals; imbalance between nuclear medicine and radiology during the first $2.5 \mathrm{y}$ of basic training during residency at the expense of nuclear medicine; uncertainty regarding the international recognition of nuclear medicine subspecialty training; and the uncertain future of nuclear medicine regarding the chances for employment and the ratio of nuclear medicine to radiology work activities. Conclusion: This study provided insight into residents' motives in pursuing or refraining from nuclear medicine subspecialization in an integrated nuclear medicine and radiology residency program. Medical imaging specialists in training hospitals and developers of curricula for nuclear medicine and radiology training should take these motives into account to ensure a sufficient outflow of newly graduated nuclear medicine specialists.
\end{abstract}

Key Words: internship and residency; nuclear medicine; radiology; training programs

J Nucl Med 2021; 62:905-909

DOI: 10.2967/jnumed.120.261503

Received Dec. 8, 2020; revision accepted Feb. 16, 2021

For correspondence or reprints, contact Ton Velleman (t.velleman@umcg.nl). Published online Mar. 12, 2021.

COPYRIGHT $\mathbb{C} 2021$ by the Society of Nuclear Medicine and Molecular Imaging.
$\mathbf{N}$ uclear medicine keeps evolving thanks to the everexpanding armament of diagnostic and therapeutic radiotracers and to continuing advances in photon detection technology. The hybrid imaging techniques that combine SPECT or PET with CT or MRI make the synergy between diagnostic nuclear medicine and radiology apparent (1). This synergy is also reflected in the structure of most nuclear medicine and radiology residency programs in the United States and Europe, in which crossover training between the 2 specialties is common (2-5).

A completely separate residency program for nuclear medicine (with a crossover internship in radiology) existed in The Netherlands until 2015 and secured a constant outflow of newly graduated nuclear medicine physicians. In 2015, an integrated residency for nuclear medicine and radiology was implemented in The Netherlands (6). A complete integration of radiology and nuclear medicine was thought to provide the best opportunities for optimal and comprehensive medical imaging, collaboration with clinical colleagues, and quality patient care, as communicated by representatives from the Dutch societies of radiology and nuclear medicine (6). At the same time, the completely separate residency program for nuclear medicine ceased to exist. The newly integrated nuclear medicine and radiology residency program offers residents a completely free choice between 1 or 2 of 8 subspecialties to pursue after the first $2.5 \mathrm{y}$ of general integrated nuclear medicine and radiology residency (6). Nuclear medicine, in the Dutch curriculum named "Nuclear Medicine and Molecular Radiology," is among these subspecialties and includes training in both diagnostic and therapeutic nuclear medicine (6). The other 7 radiology-based subspecialties are cardiothoracic radiology, abdominal radiology, interventional radiology, musculoskeletal radiology, neuroradiology and head and neck radiology, breast radiology, and pediatric radiology (6). Residents who choose the nuclear medicine subspecialty cannot subspecialize in any other field during their residency in the current program, because this would be at the expense of the time that is considered necessary to master the required nuclear medicine skills (6). Residents who successfully complete the nuclear medicine subspecialty training bear the title "nuclear radiologist."

The number of residents who choose the nuclear medicine specialty has been declining in many countries in the past few years (7-9). Importantly, a few years after the implementation of the integrated nuclear medicine and radiology residency program in 
The Netherlands, it appeared that only 14 residents had chosen the nuclear medicine specialty (7). This number was considerably lower than anticipated and can be considered a threat to the future nuclear medicine workforce. Eventually, this decline may negatively affect patient care and the future development of the specialty. The reason for this lagging interest is currently unclear and requires investigation. Such information may potentially be useful to increase recruitment of residents for the nuclear medicine subspecialty and to maintain the future nuclear medicine workforce. It may also reveal targets for improvement in other countries' integrated nuclear medicine and radiology residency programs that are similar to the program in The Netherlands.

Therefore, the purpose of this study was to explore reasons that influence a resident's decision to choose the nuclear medicine subspecialty in the integrated nuclear medicine and radiology residency program in The Netherlands.

\section{MATERIALS AND METHODS}

\section{Study Design}

The local medical ethics review board approved this prospective study (approval 202000290), which was based on a questionnaire. On voluntary participation in this study, informed consent was given.

\section{Participants}

The Netherlands has 8 teaching and training regions for nuclear medicine and radiology, with a total of 28 training hospitals. Each region consists of 1 academic and several nonacademic hospitals. All residents spend at least $1 \mathrm{y}$ of their residency in an academic hospital and at least $1 \mathrm{y}$ in a nonacademic hospital. Each region offers the same integrated nuclear medicine and radiology residency program according to the guidelines set by the Radiologic Society of The Netherlands (10).

A web questionnaire was developed and e-mailed to the residency program directors of the training hospitals, with a request that they distribute it to their residents. No reminder to return the questionnaires was sent after the initial e-mail. Both the program directors and the participating residents were informed about the purpose of the questionnaire, that is, to investigate why residents choose or do not choose the nuclear medicine subspecialty in the integrated nuclear medicine and radiology residency program. The questionnaire was accessible to the residents via an anonymous web link. Anonymous registration via Internet protocol addresses ensured unique respondents. Any personal data, including Internet protocol addresses, were not available to the investigators.

Any residents participating in the integrated nuclear medicine and radiology program in The Netherlands, regardless of their year of training, were included. Residents who were participating in the previous curriculum, in which nuclear medicine and radiology had not yet been integrated, were excluded. Partially completed questionnaires were also excluded.

Completed questionnaires digitally returned between May 27 and July 12 , 2020, were included in the study.

\section{Questionnaire}

The questionnaire was developed by 2 radiologists, 1 nuclear medicine physician, and 1 survey specialist and contained 14 closed-ended questions and 9 open-ended questions that were further analyzed.

The closed-ended questions aimed to capture the following variables from each resident: their age, sex, and teaching and training region; whether they had received any nuclear medicine education before residency (yes or no); whether they had completed or were working on a PhD thesis (yes or no); their level of interest in scientific research (expressed on a 10-point grading scale); whether they had worked in a clinic before residency (yes or no); whether they had chosen or begun nuclear medicine or subspecialty radiology subspecialty training; whether they had been inspired by someone to choose a certain subspecialty (yes or no); whether there are any circumstances that made the nuclear medicine subspecialty program in their region attractive or unattractive (yes or no); whether these circumstances had influenced the subspecialty choice (yes or no); whether future employment chances influenced the subspecialty choice (yes or no); and where they would prefer to work in the future (academic hospital, nonacademic hospital, or elsewhere).

The open-ended questions aimed to explore the answers to some of the closed-ended questions in greater depth, that is, what kind of nuclear medicine education did they receive before residency, which person inspired them to enter the integrated nuclear medicine and radiology residency program, what was their specialty during their clinical work before residency, which person inspired them to choose a certain subspecialty, which circumstances make the nuclear medicine subspecialty program in their region attractive or unattractive, how these circumstances influenced the subspecialty choice, what their opinion is on the integration of the nuclear medicine and radiology training programs, and whether they wished to share any other comments on the residency training program.

The questionnaire was digitized with Qualtrics Core XM survey software (Qualtrics, LLC, an SAP America Inc. company).

\section{Data Analysis}

Survey participants were divided into 3 groups: undecided residents (residents who were still in their first $2.5 \mathrm{y}$ of general integrated nuclear medicine and radiology residency and had not yet chosen their subspecialty), nuclear medicine residents (residents who had already begun or decided to choose nuclear medicine training), and radiology residents (residents who had already begun or decided to choose radiology training).

Answers to the closed-ended questions were compared between nuclear medicine residents and radiology residents, using the Mann-Whitney test for ordinal variables and the $\chi^{2}$ test for dichotomous and nominal variables.

Answers to the open-ended questions were qualitatively analyzed by 2 radiologists, 1 nuclear medicine physician, and 1 survey specialist to identify common categories that shape a resident's decision to choose nuclear medicine training.

$P$ values of less than 0.05 were considered statistically significant. Statistical analyses were executed using MedCalc software, version 17.2.

\section{RESULTS}

\section{Respondents}

At the time of the survey, approximately 350 residents were in the integrated nuclear medicine and radiology residency program in The Netherlands (7). All 28 program directors distributed the questionnaire to their residents. The number of questionnaires returned was 129 (estimated response rate, 36.9\%), 15 of which were excluded because they were only partially completed. Fifty-two $(46 \%)$ of the respondents were men, $60(53 \%)$ were women ( 2 did not indicate their sex), and most (89\%) were between 26 and $35 \mathrm{y}$ old. Their characteristics are shown in Table 1 . There were 35 (31\%) undecided residents, 9 (8\%) nuclear medicine residents, and $70(61 \%)$ radiology residents. Residents from each of the 8 regions were represented (Amsterdam Academic Medical Center, 6\%; Vrije Universiteit Amsterdam Medical Center, 20\%; Leiden, 5\%; Nijmegen, 9\%; Northeast Netherlands, 18\%; Southeast Netherlands, 18\%; Southwest Netherlands, 14\%; and Utrecht, 10\%).

\section{Comparison of Characteristics Between Subspecialties}

The proportion of nuclear medicine residents who had completed or were working on a $\mathrm{PhD}$ thesis $(79 \%)$ was higher than 
that of radiology residents $(57 \%)$. High interest in scientific research was also more frequent among nuclear medicine residents (67\%) than among radiology residents (26\%). In choosing their subspecialty, nuclear medicine residents were more frequently influenced by circumstances that make the nuclear medicine program in their region attractive or unattractive $(33 \%)$ than were radiology residents $(9 \%)$. In deciding on their specialty, nuclear medicine residents were also more frequently influenced by future employment chances (44\%) than were radiology residents $(19 \%)$. On the other hand, nuclear medicine residents were less likely to have received nuclear medicine education before residency $(11 \%)$ than were radiology residents (33\%). There were no other substantial differences between the nuclear medicine and radiology residents, and there were no statistically significant differences in any of the variables that were analyzed between the 2 groups ( $P$ values ranging from 0.100 to 0.981 ) (Table 1).

\section{Incentives to Choose the Nuclear Medicine Subspecialty}

In their answers to the open-ended questions, almost a third of the residents ( 9 undecided, 5 nuclear medicine, and 28 radiology) indicated reasons that they favored pursuing the nuclear medicine subspecialty. These could be grouped into 4 categories: the expertise of nuclear medicine physicians and their quality of supervision in the training hospital; opportunities to do scientific research during and after residency; the diversity of pathologic conditions, radiotracers, examinations, and therapies in the training hospital; and an expectation that the role of hybrid imaging will increase. Representative responses are listed in Supplemental Table 1 (supplemental materials are available at http://jnm.snmjournals.org).

\section{Disincentives to Choose the Nuclear Medicine Subspecialty}

In their answers to the open-ended questions, a fifth of the residents (4 undecided, 2 nuclear medicine, and 19 radiology) indicated reasons that they did not favor pursuing the nuclear medicine subspecialty. These could be grouped into 4 categories: lack of collaboration and integration between nuclear medicine and radiology in some training hospitals; imbalance between nuclear medicine and radiology during the first $2.5 \mathrm{y}$ of basic training during residency at the expense of nuclear medicine; uncertainty regarding the international recognition of nuclear medicine subspecialty training; and uncertainty about the future of nuclear medicine, regarding the chances of employment and the ratio of nuclear medicine to radiology work activities. Representative responses are listed in Supplemental Table 2.

\section{DISCUSSION}

Of the approximately 350 residents who were in the Dutch integrated nuclear medicine and radiology residency program in May-July 2020, 114 were included in this study. The estimated response rate $(36.9 \%)$ was in line with previously reported response rates for surveys in health care (11). Furthermore, because the respondents included residents from all 8 teaching and training regions in The Netherlands, the survey can be considered representative of the entire country.

The fact that no statistically significant differences in characteristics were found between nuclear medicine and radiology residents is likely due to the relatively low number of the former $(n=$ $9)$ in comparison with the latter $(n=70)$. In March 2020, the total number of residents in the nuclear medicine subspecialty program in The Netherlands was 14 (12). Assuming that 175 of the 350 residents were in the subspecialty phase of their training in March
2020, $8 \%(14 / 175)$ of residents had chosen the nuclear medicine subspecialty. In addition, the number of residents in the nuclear medicine subspecialty program in March 2020 was substantially lower than the approximately 50 nuclear medicine residents who were in training in the dedicated nuclear medicine residency program before 2015 (7), when the nuclear medicine and radiology programs were still separate. These data underline the relevance of the present study.

Although the differences in characteristics between nuclear medicine and radiology residents were not statistically significant, some interesting observations could be made. First, our data suggest that nuclear medicine residents generally have a greater affinity for scientific research than do radiology residents, as reflected by higher proportions of completed or ongoing $\mathrm{PhD}$ theses $(79 \%$ vs. $57 \%$ ) and higher interest in scientific research (67\% vs. $26 \%)$. This difference is perhaps related to the reputation of nuclear medicine as a highly innovative field, particularly in Europe, where new imaging biomarkers and nuclear theranostics have been developed in the past few years (5). In The Netherlands, theranostics currently comprises only a fraction of the daily nuclear medicine workload. Second, regional circumstances regarding nuclear medicine training (such as the availability of a wide or unique arsenal of nuclear medicine procedures or nuclear medicine staff expertise) more frequently influenced nuclear medicine residents than radiology residents in their subspecialty choice (33\% vs. 9\%). This finding suggests that attractive circumstances may persuade some individuals to pursue the nuclear medicine subspecialty but that unattractive circumstances do not necessarily deter residents from choosing it. Third, expected postresidency employment opportunities more frequently influenced nuclear medicine residents than radiology residents (44\% vs. $13 \%$ ). This finding seems plausible because the nuclear medicine workforce is currently decreasing in The Netherlands whereas the job market for radiologists is saturated. Fifth, nuclear medicine residents were less likely than radiology residents to have received nuclear medicine education before residency ( $11 \%$ vs. $33 \%)$. This observation is somewhat surprising but feeds the hypothesis that the overall quality of undergraduate nuclear medicine education in The Netherlands needs to be improved to inspire future residents to subspecialize in nuclear medicine.

The observed differences between nuclear medicine and radiology residents resonate with the results of our qualitative analysis of the open-ended questions. Among the 4 categories of reasons that residents favored pursuing the nuclear medicine subspecialty, 3 share the common denominator of showing that residents are attracted to being at the forefront of educational, scientific, and clinical expertise and innovation (expertise of nuclear medicine physicians and their quality of supervision in the training hospital; opportunities to do scientific research during and after residency; and diversity of pathologic conditions, radiotracers, examinations and therapies in the training hospital). Although it can be argued that leadership in these areas is primarily an academic task, the study suggests that any hospital accredited to offer the nuclear medicine subspecialty should fulfill and maintain a certain standard in this respect. The fourth category that motivates residents to choose the nuclear medicine subspecialty is the expectation that the role of hybrid imaging will increase in the future, which is also one of the reasons why a national taskforce decided to implement an integrated nuclear medicine and radiology residency program in The Netherlands in 2015 (6). Future studies are necessary to confirm and monitor the expected rise in hybrid imaging examinations. 
TABLE 1

Characteristics of Residents

\begin{tabular}{|c|c|c|c|c|}
\hline Variable & $\begin{array}{c}\text { Resident's subspecialty } \\
\text { Undecided }(n=35)\end{array}$ & $\mathrm{NM}(n=9)$ & Radiology $(n=70)$ & $P^{*}$ \\
\hline Age (y) & & & & $0.259^{\dagger}$ \\
\hline $20-25$ & 0 & 0 & 0 & \\
\hline $26-30$ & 21 & 2 & 24 & \\
\hline $31-35$ & 10 & 4 & 41 & \\
\hline $36-40$ & 0 & 1 & 3 & \\
\hline $41+$ & 4 & 1 & 1 & \\
\hline Not indicated & & 1 & 1 & \\
\hline Sex & & & & $0.981^{\ddagger}$ \\
\hline Male & 18 & 3 & 31 & \\
\hline Female & 17 & 5 & 38 & \\
\hline Not indicated & 0 & 1 & 1 & \\
\hline Exposure to NM education before residency & 13 & 1 & 23 & $0.342^{\ddagger}$ \\
\hline Completed or ongoing work on $\mathrm{PhD}$ thesis & 16 & 7 & 40 & $0.409^{\ddagger}$ \\
\hline Interest in scientific research & & & & $0.135^{\dagger}$ \\
\hline Low & 6 & 2 & 11 & \\
\hline Mid & 16 & 0 & 27 & \\
\hline High & 10 & 6 & 18 & \\
\hline Not indicated & 3 & 1 & 14 & \\
\hline Clinical working experience before residency & 27 & 5 & 38 & $0.777^{\ddagger}$ \\
\hline Inspired by someone to choose subspecialty & NA & 3 & 32 & $0.728^{\ddagger}$ \\
\hline Attractive circumstances for NM subspecialty & 9 & 5 & 28 & $0.595^{\ddagger}$ \\
\hline Unattractive NM subspecialty circumstances & 4 & 2 & 19 & $0.931^{\ddagger}$ \\
\hline Influence of attractive or unattractive circumstances & NA & 3 & 6 & $0.100^{\ddagger}$ \\
\hline Influence of future employment chances & NA & 4 & 13 & $0.178^{\ddagger}$ \\
\hline Preference of future working place & & & & $0.361^{\ddagger}$ \\
\hline Academic & 11 & 3 & 29 & \\
\hline Nonacademic & 19 & 3 & 30 & \\
\hline Elsewhere & 5 & 3 & 10 & \\
\hline No choice & 0 & 0 & 1 & \\
\hline
\end{tabular}

*Differences between NM and radiology residents.

${ }^{\dagger}$ According to Mann-Whitney test.

${ }^{\ddagger}$ According to $\chi^{2}$ test.

$\mathrm{NM}=$ nuclear medicine; NA = not applicable.

Of the 9 NM residents, 7 had already started NM training and 2 had decided to choose it. Of the 70 radiology residents, 47 had already started radiology training and 23 had decided to choose it.

Regarding the 4 categories of reasons that residents did not favor pursuing the nuclear medicine subspecialty, one potential obstacle is the lack of collaboration and integration between nuclear medicine and radiology in some training hospitals. It can be speculated that historical differences in clinical workloads, workflows, and reimbursement between the 2 departments may play a role. If and how general collaboration can be improved, and whether the 2 subspecialties should operate as a single department or as 2 different ones, are complicated issues that require further investigation. Another potential obstacle is the imbalance between nuclear medicine and radiology - at the expense of nuclear medicine-during the first $2.5 \mathrm{y}$ of basic training during residency.
However, dedicating more time to nuclear medicine would then be at the expense of radiology training or would require prolonging the total duration of the residency. The remaining obstacles to choosing subspecialty training in nuclear medicine relate to uncertainty about whether such training will be internationally recognized, whether there will be sufficient future chances of employment, and whether there will be a sufficient ratio of nuclear medicine to radiology work activities. These knowledge gaps need to be urgently addressed because they hinder recruitment of residents for the nuclear medicine subspecialty.

Previous studies surveying radiology residents in the United States (13), the United Kingdom (14), and Saudi Arabia (15) 
found that among the most popular factors influencing subspecialty choice were strong personal interest, intellectual challenge, a successful or enjoyable rotation during training, the availability of advanced or multimodality imaging, the ability to have a direct impact on patient care, favorable working hours and on-call commitments, and good job prospects. Likewise, in the present study, the role of multimodality imaging and job opportunities were influential. However, other motivating factors largely differed between the present study and the 3 previous studies (13-15), most likely because the latter did not specifically investigate why residents choose or refrain from subspecialization in nuclear medicine.

The present study had some limitations. First, the results should be considered a snapshot in time. New insights may arise from future developments such as adjustments to the Dutch integrated nuclear medicine and radiology curriculum, scientific developments that lead to clinical paradigm shifts (e.g., the expansion of theranostics and the clinical implementation of artificial intelligence), and employment opportunities. Nevertheless, our results provide a baseline framework that can be useful to all stakeholders who wish to increase the recruitment of nuclear medicine residents. This recruitment needs further monitoring before a definitive conclusion can be made on the viability of the integrated curriculum. Second, this study did not investigate the role of postresidency fellowships, which, in combination with the training received during residency, may allow a resident to become an accredited subspecialist in both nuclear medicine and a radiology-based field. Third, because the questionnaire was returned anonymously, it was not possible to ask for specific feedback from residency program directors and other medical imaging specialists in the training hospitals.

\section{CONCLUSION}

This study provided insight into what motivates residents to pursue or refrain from nuclear medicine subspecialization in an integrated nuclear medicine and radiology program. Medical imaging specialists in training hospitals and developers of training curricula should consider these motives to ensure a sufficient outflow of newly graduated nuclear medicine specialists.

\section{DISCLOSURE}

No potential conflict of interest relevant to this article was reported.

\section{ACKNOWLEDGMENTS}

We thank the program directors who distributed the questionnaire to their residents, and the residents who participated.
KEY POINTS

QUESTION: In the integrated residency program for nuclear medicine and radiology in The Netherlands, why do residents choose to subspecialize in nuclear medicine and why not?

PERTINENT FINDINGS: The survey found no statistically significant differences in characteristics between nuclear medicine residents and radiology residents. The results provided insight into what motivates residents to pursue or refrain from nuclear medicine subspecialization in an integrated residency program.

IMPLICATIONS FOR PATIENT CARE: Those who develop curricula for nuclear medicine and radiology training can use the motives revealed in this study to ensure a sufficient outflow of newly graduated specialists.

\section{REFERENCES}

1. Graham MM, Metter DF. Evolution of nuclear medicine training: past, present, and future. J Nucl Med. 2007;48:257-268.

2. Arevalo-Perez J, Paris M, Graham MM, Osborne JR. A perspective of the future of nuclear medicine training and certification. Semin Nucl Med. 2016;46: 88-96.

3. DR certified requirements. American Board of Nuclear Medicine website. https:// www.abnm.org/index.php/dr-certified-requirements/. Accessed May 6, 2021.

4. Muylle K, Maffioli L. Nuclear medicine training in Europe: "all for one, one for all." J Nucl Med. 2017;58:1904-1905.

5. Czernin J, Sonni I, Razmaria A, Calais J. The future of nuclear medicine as an independent specialty. J Nucl Med. 2019;60(suppl 2):3S-12S.

6. van Schaik JP, Bennink RJ. Integrated residency in radiology and nuclear medicine in The Netherlands. $J$ Nucl Med. 2017;58(7):9N-11N.

7. Aantal registraties specialisten/aios. Voorop voor Dokter en Zorg website. https:// www.knmg.nl/opleiding-herregistratie-carriere/rgs/registers/aantal-registratiesspecialistenaois.htm. Accessed May 6, 2021.

8. Harolds JA, Guiberteau MJ, Oates ME. Recruitment into a combined radiology/ nuclear medicine subspecialty. J Am Coll Radiol. 2017;14:122-124.

9. Ruddell JH, Eltorai AEM, Tang OY, et al. The current state of nuclear medicine and nuclear radiology: workforce trends, training pathways, and training program websites. Acad Radiol. 2020;27:1751-1759.

10. CORONA opleidingsplan. Nederlandse Vereniging voor Radiologie website. https://www.radiologen.nl/secties/concilium-radiologicum/documenten/coronaopleidingsplan. Published June 25, 2020. Accessed May 6, 2021.

11. Cunningham CT, Quan H, Hemmelgarn B, et al. Exploring physician specialist response rates to web-based surveys. BMC Med Res Methodol. 2015;15:32

12. Nederlandse vereniging voor radiologie. Nederlandse Vereniging voor Radiologie website. https://www.radiologen.nl. Accessed May 6, 2021.

13. Arnold RW, Goske MJ, Bulas DI, Benya EC, Ying J, Sunshine JH. Factors influencing subspecialty choice among radiology residents: a case study of pediatric radiology. J Am Coll Radiol. 2009;6:635-642.

14. Parvizi N, Bhuva S. A national UK survey of radiology trainees special interest choices: what and why? Br J Radiol. 2017;90:20170338.

15. Alturki ST, Albusair MK, Alhumaid F, et al. Factors influencing the choice of radiology subspecialty among radiology trainees in Saudi Arabia. Cureus. 2019;11:e6149. 